${ }^{1}$ Servicio de Medicina Interna, Área Médica, Hospital del Salvador. ¿Unidad de Paciente Crítico, Hospital del Salvador

Recibido el 27 de diciembre de 2009, aceptado el 23 de marzo de 2011.

Correspondencia a:

Dr. Mauricio Salinas F.

Servicio de Medicina

Interna, Área Médica,

Hospital del Salvador.

Avda. Salvador 364,

Providencia. Santiago.

Chile.

Fono: 5753532

E-mail:mrsalinas@vtr.net

\section{Rabdomiólisis e insuficiencia renal aguda por consumo de cocaína: caso clínico}

\author{
RODRIGO CARRASCO ${ }^{1}$, MAURICIO SALINAS ${ }^{1}$, VÍCTOR ROSSEL ${ }^{2}$
}

\section{Rhabdomyolysis and acute renal failure after cocaine overdose. Report of one case}

Rhabdomyolysis caused by cocaine abuse is multifactorial, involving tissue ischemia secondary to vasoconstriction and cellular damage caused by the drug. Renal failure may or may be not associated to rhabdomyolysis. We report a 41-year-old male admitted with a severe rhabdomyolysis after a cocaine overdose. In spite of a vigorous hydration and alkalization, he developed acute renal failure. Renal function recovered after several weeks of dialysis.

(Rev Med Chile 2011; 139: 480-483).

Key words: Acute kidney injury; Cocaine; Rhabdomyolysis.
$\mathrm{E}$ n la última década, son numerosos los reportes médicos que han descrito cuadros clínicos asociados al uso de drogas ilícitas, dentro de las cuales la cocaína es una de las más prevalentes. El consumo de cocaína se ha asociado con diversas complicaciones, siendo las más frecuentes las cardiovasculares y neurológicas y menos comunes pulmonares, digestivas, hematológicas y renales ${ }^{1}$.

A continuación hemos querido centrar nuestra atención en la falla renal aguda asociada al consumo de cocaína que es una complicación poco frecuente. Se ha descrito que $30 \%$ de los pacientes que ingresan con un cuadro clínico de rabdomiólisis por uso de cocaína desarrollan falla renal, representando este último grupo a $5 \%$ de los pacientes consumidores de cocaína que asisten al servicio de urgencia ${ }^{2}$. A propósito de un caso clínico que estuvo en el Hospital del Salvador, hemos realizado una breve revisión de la literatura médica, con énfasis en los mecanismos fisiopatológicos.

\section{Caso clínico}

Paciente varón de 41 años con antecedentes de consumo de cocaína desde 1997, intento de suicidio en el año 2005, por lo cual tuvo varias fracturas, quedando secuelado con trastorno de incontinencia vesical y rectal.

Sin consumo de drogas desde el año 2005, reinició consumo de cocaína y alcohol a principios de septiembre de 2008. Fue llevado al Hospital del Salvador el día 8 de octubre de 2009, luego de una semana de inhalación diaria de cocaína, aproximadamente seis gramos en total, refirió el paciente, con agitación, conducta agresiva y alucinaciones visuales. Fue hospitalizado, requiriendo contención y sedación, secundario a lo cual presentó depresión respiratoria, requirió intubación y traslado a UCI para ventilación mecánica invasiva.

$\mathrm{Al}$ ingreso a UCI destacaba en el examen físico erosiones en región cervical y extremidades, con signos vitales estables. En los exámenes de ingreso destacaba BUN/creatinina de $33 \mathrm{mg} / \mathrm{dL} / 2,58 \mathrm{mg} /$ dL, creatinkinasa (CK) $34.686 \mathrm{U} / \mathrm{L}$, amilasa 515 $\mathrm{U} / \mathrm{L}$, deshidrogenasa láctica $(\mathrm{LDH}) 1.235 \mathrm{U} / \mathrm{L}$, $\mathrm{pH} 7,33, \mathrm{HCO}_{3} 13,8 \mathrm{mmol} / \mathrm{L}$. El examen de orina completa era normal y no se midieron electrolitos urinarios. La evolución de los exámenes se resume en la Tabla 1.

Se trató con aporte vigoroso de cristaloides, alcanzando niveles adecuados de presión venosa central y se administró bicarbonato para alcalinizar orina. Evoluciona con débitos urinarios de 200 a $300 \mathrm{ml}$ día, con CK en alza y deterioro progresivo 
Rabdomiólisis e insuficiencia renal aguda por cocaína - R. Carrasco et al

Tabla 1. Evolución de los exámenes de laboratorio durante la primera semana de hospitalización

\begin{tabular}{|c|c|c|c|c|c|c|c|c|}
\hline & Día 1 & Día 2 & Día 3 & Día 4 & Día 5 & Día 6 & Día 7 & Día 8 \\
\hline Hematocrito (\%) & 42,1 & 39 & 36 & - & 34,4 & 34,5 & - & 34,1 \\
\hline Hemoglobina (g/dL) & 14,3 & 13,5 & 12,4 & - & 11,8 & 11,9 & - & 11,8 \\
\hline Leucocitos ( $\mu \mathrm{L})$ & 11.300 & 16.200 & 13.200 & 11.500 & 11.700 & 13.500 & 11.200 & 11.600 \\
\hline Plaquetas ( $\mu \mathrm{L}$ ) & 164.000 & 89.700 & 91.000 & & 84.200 & & 174.000 & 223.000 \\
\hline N. ureico (mg/dL) & 33 & 38 & 50 & 37 & 51 & 49 & 49 & 45 \\
\hline Creatinina (mg/dL) & 2,9 & 3,1 & 5,0 & 5,7 & 8,9 & 7,5 & 7,0 & 6,3 \\
\hline Sodio (mmol/L) & 134 & 144 & 138 & 137 & 137 & 135 & 136 & 136 \\
\hline Cloro (mmol/L) & 112 & 111 & 95 & 94 & 97 & 108 & 99 & 98 \\
\hline Potasio (mmol/L) & 3,4 & 3,6 & 3,3 & 4,4 & 5,2 & 5,1 & 4,6 & 4,5 \\
\hline CK (U/L) & 34.686 & 129.712 & 101.109 & 89.634 & 69.412 & & 23.811 & \\
\hline Bilirrubina total (mg/dL) & 0,99 & 1,96 & 2,58 & 4,55 & 4,17 & 2,9 & 2,19 & 1,89 \\
\hline Bilirrubina directa (mg/dL) & 0,33 & 1,09 & 1,39 & 2,85 & 2,74 & 1,7 & 1,15 & 0,97 \\
\hline GPT (UI/L) & 119 & 1634 & 427 & 139 & 2.589 & 829 & 1.248 & 999 \\
\hline GOT (UI/L) & 623 & 3.432 & 590 & 52 & 2.440 & 899 & 800 & 637 \\
\hline GGT (UI/L) & 21 & 25 & 50 & 112 & 251 & 481 & 552 & 491 \\
\hline Fosfatasas alcalinas (UI/L) & 79 & 81 & 90 & 90 & 117 & 165 & 217 & 210 \\
\hline pH & 7,35 & 7,46 & 7,43 & 7,5 & 7,51 & 7,51 & 7,52 & 7,55 \\
\hline Bicarbonato (mmol/L) & 13,8 & 20 & 28,8 & 32,2 & 27,9 & 27,0 & 27,2 & 22,6 \\
\hline $\mathrm{PCO}_{2}(\mathrm{mmHg})$ & 25,8 & 27,7 & 42,6 & 40,9 & 34,7 & 33,3 & 33,0 & 27,0 \\
\hline
\end{tabular}

de creatinina, por lo que inició hemodiálisis a partir del quinto día de hospitalización. No requirió uso de drogas vasoactivas y fue extubado a las 24 horas de ingreso a UCI sin incidentes.

Se realizó ecografía renal que informó tamaño y diferenciación corticomedular adecuados y ausencia de elementos obstructivos en el sistema pielocaliciario; ecografía abdominal mostró hígado y vía biliar de características normales. El ecocardiograma mostró dilatación leve de aurícula y ventrículo izquierdo, reflujo mitral moderado y fracción de eyección de 54\%. Se realizó examen toxicológico en sangre que fue positivo para cocaína en concentración de $52 \mathrm{ng} / \mathrm{ml}$. Esta muestra fue tomada aproximadamente 36 horas después del último consumo.

El paciente evolucionó sin otras complicaciones, con falla renal persistente por lo cual fue trasladado a unidad de menor complejidad al día 21, continuando hemodiálisis trisemanal. Posteriormente, recuperó función renal.
Desde el punto de vista psiquiátrico, se concluyó que el paciente presentaba un trastorno bipolar además de su poliadicción.

\section{Discusión}

La cocaína se encuentra disponible en dos formas: hidrocloruro de cocaína y alcaloide de cocaína (pasta base/crack), que es elaborado mediante alcalinización salina, seguido por la extracción con solventes no polares. Ambas formas son bien absorbidas por la mayoría de las membranas mucosas ${ }^{3,4}$.

La cocaína inhibe la recaptación de catecolaminas en los terminales nerviosos presinápticos, bloquea la recaptación de norepinefrina en tejidos inervados simpáticamente e induce la liberación de norepinefrina y epinefrina de la médula adrenal ${ }^{1,5}$.

Se han descrito diversas nefropatías asociadas con el abuso de este tipo de drogas: síndrome 
nefrótico, glomerulonefritis aguda, amiloidosis y nefritis intersticial ${ }^{6,7}$. Los mecanismos por los que se producen las alteraciones ya señaladas son poco conocidos. La mayor parte de la evidencia científica al respecto proviene de estudios en animales, casos clínicos y series de casos pequeñas, donde es frecuente el consumo de más de una droga.

No se ha establecido correlación exacta entre niveles plasmáticos y cuadro clínico; se han descrito niveles plasmáticos de $4.697 \mathrm{ng} / \mathrm{ml}$ de cocaína en pacientes con convulsiones, pocas horas luego del consumo.

Para esta revisión hemos separado la insuficiencia renal asociada a cocaína en aquellas con y sin rabdomiólisis, lo cual tiene implicancias terapéuticas y resulta práctica desde un punto de vista clínico.

\section{Mecanismos de falla renal mediados por rabdomiólisis}

La rabdomiólisis inducida por cocaína ha sido documentada ampliamente ${ }^{8}$. Las drogas tienen un efecto tóxico directo muscular, pero también pueden causar indirectamente rabdomiólisis, al producir compromiso de conciencia e inmovilización prolongada9.

El marcado incremento de la actividad simpaticomimética inducida por cocaína provoca vasoconstricción arterial, isquemia e infartos a nivel muscular ${ }^{10}$. Otro mecanismo descrito es la inhibición de la recaptación de catecolaminas en receptores alfa adrenérgicos lo que eleva el calcio intracelular en las células musculares ${ }^{11}$.

Los consumidores de cocaína que se presentan con injuria muscular, a menudo presentan otros problemas: delirium, agitación, fiebre, colapso cardiovascular o dolor torácico, debido a que todas estas situaciones tienen en común una exposición a mayores niveles plasmáticos de cocaína. La rabdomiólisis es un signo de alerta de intoxicación grave y se debe buscar en pacientes con mialgias $\mathrm{o}$ las otras manifestaciones descritas.

La injuria muscular puede ocurrir después del uso de cocaína oral o nasal, pero ocurre más comúnmente después de uso intravenoso o después de fumar su forma alcaloide (Crack/Pasta base), ya que se logran concentraciones más altas. El daño muscular puede ocurrir después de consumo único o de uso repetido y generalmente se presenta dentro de horas luego de la administración ${ }^{3}$. El rango de elevación de CK varía desde unas pocas veces el valor normal, hasta marcadas elevaciones mayores de $50.000 \mathrm{U} / \mathrm{L}$. En un reporte el promedio de elevación máxima de CK de 39 pacientes con rabdomiólisis asociada a cocaína fue de $12.187^{3}$. El riesgo de falla renal aguda por mioglobina es directamente proporcional a los niveles de CK. Frecuentemente existen además, otros factores de riesgo: fiebre, agitación, hipotensión, coma o uso de otras drogas que también producen rabdomiólisis: heroína, anfetaminas o fenciclidina ${ }^{1}$.

En el caso presentado, hubo agitación inicial y luego compromiso de conciencia. Además había consumo reiterado por varios días. No se detectó consumo de otras drogas, excepto benzodiacepinas.

El tratamiento fundamental de estos pacientes es el aporte de grandes cantidades de cristaloides y alcalinización de la orina. El pH urinario objetivo es 6,5 o superior ${ }^{12}$.

\section{Mecanismos de falla renal no mediados por rabdomiólisis}

Se han reportado casos de falla renal aguda sin rabdomiólisis, lo que inicialmente se atribuyó a intensa vasoconstricción. Sin embargo, este mecanismo por sí solo, no sería suficiente ${ }^{1}$.

La endotelina (ET) ha sido implicada en la disfunción vascular que es inducida por consumo de cocaína ${ }^{1}$. Existe alta densidad de receptores de endotelina-1 (ETR-1) en el músculo liso vascular renal $^{13}$. El incremento en la producción de ET-1 provoca disminución del flujo sanguíneo renal y de la velocidad de filtración glomerular ${ }^{14}$. Se ha documentado niveles de ETR-1 elevados en el plasma y orina de mujeres embarazadas que consumen cocaína ${ }^{1,15}$. Además, se ha demostrado participación del eje renina-angiotensina-aldosterona: la liberación de ET inducida por cocaína, es inhibida por el captopril y lisinopril en cultivos de células endoteliales humanas y bovinas ${ }^{15}$. La respuesta de la presión arterial también involucra la vía del óxido nítrico $(\mathrm{NO})$. En ratas tratadas con un inhibidor de la NO sintasa, se ha demostrado $80 \%$ de reducción en la respuesta presora, al exponerlas a la acción de la cocaína ${ }^{17}$.

Las células endoteliales producen enzima convertidora de angiotensina en forma endógena, sugiriendo que el efecto de los IECA en la presión arterial y función cardiovascular puede ser debido a efectos locales en las células endoteliales ${ }^{16}$. El captopril regula negativamente la liberación de 
Rabdomiólisis e insuficiencia renal aguda por cocaína - R. Carrasco et al

ET-1 en cultivos de células endoteliales ${ }^{17}$; en un experimento en que ratas fueron expuestas a niveles letales de cocaína, el uso de captopril y diazepam, incrementó el tiempo de sobrevida ${ }^{18}$.

Finalmente, la activación del sistema renina angiotensina aldosterona puede llevar a la fibrosis renal, por estimulación del factor de crecimiento transformante beta, en el contexto de injuria crónica ${ }^{1}$.

\section{Comentario final}

El uso de cocaína representa un problema importante en nuestro medio. Los pacientes con antecedentes de consumo de cocaína pueden presentarse con falla renal aguda, insuficiencia renal crónica, nefritis intersticial o hipertensión arterial maligna. En los pacientes con insuficiencia renal aguda debe buscarse rabdomiólisis, ya que esta tiene un tratamiento específico y efectivo.

El estudio de los mecanismos fisiopatológicos y moleculares involucrados en el daño renal asociado al consumo de esta drogas requiere mayor investigación.

\section{Referencias}

1. Nzerue CM, Hewan-Lowe K, Riley LJ Jr. Cocaine and the kidney: a synthesis of pathophysiologic and clinical perspectives. Am J Kidney Dis 2000; 35: 783-95.

2. Brody SL, Wrenn KD, Wilber MM, Slovis CM. Predicting the severity of cocaine-associated rhabdomyolysis. Ann Emerg Med 1990; 19: 1137-43.

3. Roth D, Alarcón FJ, Fernández JA, Preston RA, Bourgoignie JJ. Acute rhabdomyolysis associated with cocaine intoxication. N Engl J Med 1988; 319: 673-7.

4. Bemanian S, Motallebi M, Saeid. Case report: Cocaineinduced renal infarction: report of a case and review of the literature. BMC Nephrology 2005; 6: 10.
5. Chiuech CC, Kopin IJ. Centrally mediated release by cocaine of endogenous epinephrine and norepinephrine from the sympathoadrenal medullary system of unanesthetized rats. J Pharmacol Exp Ther 1978; 205: 148-54.

6. Pitts WR, Lange RA, Cigarroa JE, Hillis DL. Cocaineinduced myocardial ischemia and infarction: Pathophysiology, recognition and management. Prog Cardiovasc Dis 1997; 40: 65-76.

7. Kimmel PL, Alam S, Lew SQ. Renal disease in patients with substance abuse. In: Nephrology, edited by Schena FP, London, McGraw-Hill, 2001; 237-43.

8. Jaffe JA, Kimmel PL. Chronic Nephropathies of Cocaine and Heroin Abuse: A Critical Review. Clin J Am Soc Nephrol 2006; 1: 655-67.

9. O'Connor G, McMahon G. Complications of heroin abuse. Eur J Emerg Med 2008; 15: 104-6.

10. Zamora-Quezada JL, Dinerman H, Stadecker MJ, Kelly J. Muscle and skin infarction after free-basing cocaine (crack). Ann Intern Med 1988; 108: 564-6.

11. Parks JM, Knochel JP. Case report: Cocaine-associated rhabdomyolysis. Am J Med Sci 1989; 297: 334-6.

12. Sauret JM, Marinides G, Wang GK. Rhabdomyolysis. Am Fam Physician 2002; 65: 907-12.

13. Kohan DE. Endothelins in normal and diseased kidney. Am J Kidney Dis 1997; 29: 2-25.

14. Kon V, Yoshioka T, Fogo A, Ichikawa I: Glomerular actions of endothelin in vivo. J Clin Invest 1989; 83: 1762-7.

15. Hendricks-Muñoz KD, Gerrets PR, Higgins RD, Muñoz JL, Caines VV. Cocaine-stimulated endothelin-1 release is decreased by ACE inhibitors in cultured endothelial cells. Cardiovasc Res 1996; 31: 117-23.

16. Mo W, Singh AK, Arruda JA, Dunea G. Role of nitric oxide in cocaine-induced acute hypertension. Am J Hypertens 1998; 11: 708-14.

17. Momose N, Fukuo K, Morimoto S, Ogihara T. Captopril inhibits endothelin-1 secretion from endothelial cells through bradykinin. Hypertension 1993; 21: 921-4.

18. Trouve R, Latour C, Nahas G. Cocaine and the renin angiotensin system. Adv Biosci 1991; 80: 165-76. 